\title{
Avian influenza outbreak: update
}

Published at www.cmaj.ca on Jan. 30, 2004. Revised Feb. 9, 2004.

Background and epidemiology:

Emergency preparedness means preparing for the worst while hoping for the best and learning from the past while anticipating the future. In 1999 the World Health Organization (WHO) issued an influenza pandemic preparedness plan ${ }^{1}$ to guide public health officials in the event of the emergence of a novel influenza virus, such as the avian influenza $\mathrm{A}(\mathrm{H} 5 \mathrm{~N} 1)$ virus, which is currently causing outbreaks of human cases in Vietnam and Thailand. As of Feb. 9, 2004, there were 18 laboratory-confirmed human cases (13 fatal) reported in Vietnam since December 2003 and 5 laboratory-confirmed human cases (all fatal) reported in Thailand. These cases coincide with unprecedented epidemics of avian influenza $\mathrm{A}(\mathrm{H} 5 \mathrm{~N} 1)$ infection in bird populations in Cambodia, mainland China, Indonesia, Japan, South Korea, Vietnam and Thailand. Laos is awaiting laboratory subtyping confirmation, and Pakistan and Taiwan have reported avian influenza $\mathrm{A}$ in poultry but not the H5N1 strain.

Avian influenza A(H5N1) first infected humans in 1997, in Hong Kong: 18 people were admitted to hospital, and 6 died. ${ }^{2}$ The virus was transmitted directly from birds to humans. In 2003, 2 cases of avian influenza $\mathrm{A}(\mathrm{H} 5 \mathrm{~N} 1)$ infection occurred among members of a Hong Kong family who had travelled to China. One person died. How or where these 2 people became infected was not determined.

With the current outbreak, staff from the US Centers for $\therefore$ Disease Control and Prevention (CDC) and Health Canada have travelled to affected areas to work with WHO and local public health officials to evaluate the situation. The investigation is focusing on characterizing the virus isolated from human cases and poultry, determining how people became infected and increasing surveillance to determine whether people are continuing to be infected. Preliminary results of DNA sequencing of the $\mathrm{H} 5 \mathrm{~N} 1$ strain isolated in the Vietnam outbreak show significant differences between that strain and the strains obtained during the Hong Kong outbreaks in 1997 and 2003, which indicates that the virus has mutated. The preliminary results also reveal that all of the genes of the Vietnam strain are still of avian origin, which means that the virus has not yet acquired genes from influenza strains that infect humans. Such an acquisition would increase the likelihood that an influenza virus of avian origin could be readily transmitted from one human to another. Human cases are believed to be from contact with chickens or their waste, not from eating them or their eggs. In the current outbreak, there is no evidence of person-to-person transmission, with the possible exception of 2 infected sisters in Vietnam, whose cases are still under investigation. Efficient person-toperson transmission is a possible tipping point in the eruption of an influenza A pandemic.

Of the 3 types of influenza, influenza $A$, which is found in many different animals and has the potential to cross species, has been implicated in the 3 flu pandemics in the 20th century (1918, 1957 and 1968). History tells us that pandemics occur when 3 conditions are met: the emergence of an influenza A virus whose hemagglutinin subtype is completely different from that of strains circulating in humans for many preceding years; a high proportion of susceptible people in the community (i.e., a population with low antibody titres to the new strain); and efficient person-to-person transmissibility of the new virus with accompanying human disease. ${ }^{1}$

The WHO influenza pandemic preparedness plan outlines the steps to be taken following the appearance of a new influenza strain in a single human case (phase 0 , preparedness level 1), confirmation of 2 or more human cases of infection (phase 0, level 2) and confirmation of human transmission (phase 0, level 3). By Feb. 9, the plan had escalated to phase 0 , level 2. The actions to be taken by WHO in phase 0 , level 2 include assisting in the outbreak

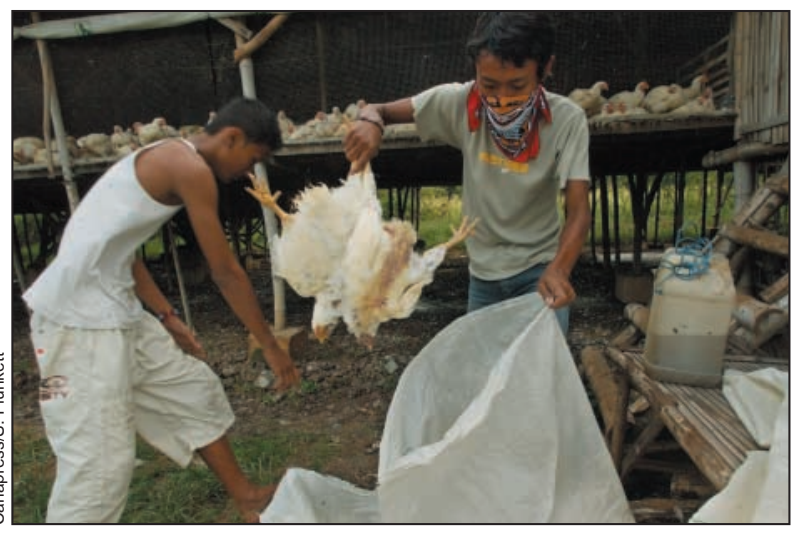

Chicken farmers disposing of their dead chickens in the Indonesian village of Gresik. On Jan. 26, the World Health Organization issued interim recommendations for the protection of people involved in the mass culling of birds potentially infected with the avian influenza $\mathrm{A}(\mathrm{H} 5 \mathrm{~N} 1)$ virus (www.wpro.who.int/avian/docs/recommendations.asp).

investigation, promoting enhanced surveillance regionally and internationally, and developing and evaluating vaccines against the new influenza strain.

Clinical management: The reported signs and symptoms of avian influenza in humans have ranged from typical flu-like symptoms (e.g., fever, cough, sore throat and muscle aches) to eye infections, pneumonia, acute respiratory distress syndrome (ARDS), multiple organ failure, lymphopenia, elevated liver enzyme levels and abnormal clotting profiles.,

At present, the CDC and 


\section{Practice}

For up-to-date information check the following Web sites:

- Health Canada: www.hc-sc .gc.ca/english/diseases/flu lavian.html

- WHO: www.who.int/csr /disease/avian_influenza/en

- CDC: www.cdc.gov/flu lavian/index.htm

- Travel advisories: www .hc-sc.gc.ca/pphb-dgspsp /tmp-pmv/disarch_e.html \#influenza
Health Canada recommend enhanced surveillance efforts by all public health departments, hospitals and clinicians. The intent is to identify patients who have unexplained pneumonia, ARDS or severe respiratory illness and who have travelled to an implicated country - one experiencing an outbreak of avian influenza $\mathrm{A}(\mathrm{H} 5 \mathrm{~N} 1)$ infection in bird or human populations within 10 days from the onset of symptoms. Physicians are advised to isolate the patient, initiate droplet precautions and contact their local medical officer of health for further discussions if an epidemiological link is apparent. Since this situation may change rapidly, readers are advised to visit Heath Canada's Web site (www.hc-sc.gc.ca/pphb -dgspsp/h5n1/index.html) for the most up-to-date table of areas affected by avian influenza $\mathrm{A}(\mathrm{H} 5 \mathrm{~N} 1)$

Prevention: $\mathrm{WHO}$ is moving forward with the procedures needed to rapidly produce a new influenza vaccine capable of protecting people against the $\mathrm{H} 5 \mathrm{~N} 1$ strain of avian influenza A recently detected in Vietnam. The process takes time. The virus for the vaccine is grown in chicken embryos; however, because H5N1 is so deadly to chickens, the virus must first be modified through "reverse genetics," whereby selected genetic information from the virus obtained from actual cases is merged with a laboratory virus. The aim is to produce a virus that confers protective immunity and can be modified so that it is no longer lethal to chicken embryos used in vaccine production. Once the prototype virus is produced, clinical trials will begin to determine optimum dosage and schedule.

Efforts are also underway to evaluate therapeutic options for treating and preventing influenza A(H5N1) infection. Preliminary genetic tests conducted in CDC laboratories in Atlanta, London and Hong Kong suggest that the H5N1 strain is resistant to amantadine and rimantadine but is believed to be susceptible to neuraminidase inhibitors. ${ }^{5}$ Further tests are underway to confirm this.

WHO has recommended urgent, rapid culling of infected and exposed bird populations to eliminate the reservoir of the $\mathrm{H} 5 \mathrm{~N} 1$ strain, similar to the culling operation in Hong Kong in 1997 that many experts believe averted an influenza pandemic. In that culling, an estimated 1.5 million birds were destroyed within 3 days by government workers who were trained and appropriately protected with masks, gloves and gowns. Subsequent investigations detected $\mathrm{H} 5$ antibodies in about $3 \%$ of the people involved in the culling, $17 \%$ of poultry workers, $3.7 \%$ of exposed health care workers and $0.7 \%$ of unexposed health care workers. ${ }^{6}$ No cases of severe respiratory disease occurred.

In addition, WHO has discouraged the practice of marketing live poultry directly to consumers in areas currently experiencing outbreaks of avian influenza $\mathrm{A}(\mathrm{H} 5 \mathrm{~N} 1)$. Some countries have introduced trade restrictions to protect animal health; however, available data do not suggest that processed poultry products (i.e., refrigerated or frozen carcasses and products derived from them) or eggs from affected areas pose a public health risk. The virus is killed by adequate heat. The importance of good food hygiene practices, including hand washing, prevention of crosscontamination and thorough cooking (to $70^{\circ} \mathrm{C}$ ), cannot be overemphasized.

\section{Erica Weir}

CMA7

Tom Wong

Centre for Infectious Disease

Prevention and Control

Health Canada

Ottawa, Ont.

Ian Gemmill

Medical Officer of Health

Kingston, Frontenac and Lennox \& Addington Health Unit

Kingston, Ont.

\section{References}

1. World Health Organization. Influenza pandemic preparedness plan. The role of $W H O$ and guidelines for national or regional planning. Geneva: The Organization; April 1999. Available www.who.int/csr/resources/publications /influenza/WHO_CDS_CSR EDC_99 1/en (accessed 2004 Jan 29).

2. Isolation of avian influenza $\mathrm{A}(\mathrm{H} 5 \mathrm{~N} 1)$ viruses from humans - Hong Kong, May-December 1997. MMWR Morb Mortal Wkly Rep 1997;46:1204-7.

3. Chan PKS. Outbreak of avian influenza A (H5N1) virus infection in Hong Kong in 1997. Clin Infect Dis 2002;34:S58-64.

4. Yuen KY, Chan PKS, Peiris M, et al. Clinical features and rapid viral diagnosis of human disease associated with avian influenza A $\mathrm{H} 5 \mathrm{~N} 1$ virus. Lancet 1998;351:467-71.

5. Altman LK. Avian flu said to be resistant to a main flu-fighting drug. Nez York Times 2004 Jan 25. Available: www.nytimes.com/2004/01/25/health /25BIRD.html (accessed 2004 Jan 29).

6. Buxton Bridges C, Katz JM, Seto WH, Chan PK, Tsang D, Ho W, et al. Risk of influenza A (H5N1) infection among health care workers exposed to patients with influenza A (H5N1), Hong Kong. f Infect Dis 2000;181:344-8. 